\title{
Contributed Paper
}

\section{Plasma Experiments Using a New 170 GHz EC System and a Simple Model for Plasma Production on the TRIAM-1M}

\author{
HASEGAWA Makoto, HANADA Kazuaki, ITOH Satoshi, NAKAMURA Kazuo, ZUSHI Hideki, \\ SAKAMOTO Mizuki, JOTAKI Eriko, KULKARNI Sanjay V. '), IYOMASA Atsuhiro, KAWASAKI Shoji, \\ NAKASHIMA Hisatoshi and NAGASAKI Kazunobu ${ }^{2)}$ \\ Advanced Fusion Research Center, Research Institute for Applied Mechanics, Kyushu University, \\ Kasuga 816-8580, Fukuoka, Japan \\ ${ }^{1)}$ Institute for Plasma Research, Gandhinagar, Gujarat, India \\ ${ }^{2)}$ Institute of Advanced Energy, Kyoto University, Japan \\ (Received 22 June 2002 / Accepted 8 October 2003)
}

\begin{abstract}
An electron cyclotron heating $(\mathrm{ECH})$ system has been installed on the TRIAM-1M tokamak, which produces a $170 \mathrm{GHz}$ microwave up to $260 \mathrm{~kW}$ at the window of the gyrotron for $5 \mathrm{sec}$. After the Matching Optical Unit (MOU) converts the microwave to a Gaussian beam, a microwave power of $200 \mathrm{~kW}$ is transmitted by a corrugated waveguide of $63.5 \mathrm{~mm}$ in diameter. Tests confirmed these specifications, and the fundamental ordinary electron cyclotron (EC) wave of $170 \mathrm{GHz}$ up to $120 \mathrm{~kW}$ was injected into the vacuum vessel of the TRIAM-1M in order to ionize neutral hydrogen gas to make source plasma, which is expected to reduce flux consumption in the case of current start-up by means of Ohmic heating $(\mathrm{OH})$ coils. Though the breakdown does not occur at the input RF power, $P_{\mathrm{RF}}=$ $40 \mathrm{~kW}$ with the neutral gas pressure, $p=1.3 \times 10^{-3} \mathrm{~Pa}$, high-density plasma (more than $0.7 \times 10^{19} \mathrm{~m}^{-3}$ ) is produced at $P_{\mathrm{RF}}=100 \mathrm{~kW}$. In the range of $P_{\mathrm{RF}}=40-100 \mathrm{~kW}$, the electron density is proportional to $P_{\mathrm{RF}}$.
\end{abstract}

\section{Keywords:}

electron cyclotron heating, $170 \mathrm{GHz}$ EC wave, ECH system, breakdown, pre-ionization, superconducting tokamak

\section{Introduction}

Electron cyclotron (EC) waves are utilized for plasma heating, current drive, and reduction of the flux consumption of Ohmic heating $(\mathrm{OH})$ coils. One of the recent requirements of the electron cyclotron heating $(\mathrm{ECH})$ system is the development of the gyrotron, which should demonstrate an output power of more than $1 \mathrm{MW}$, pulse duration in excess of $10 \mathrm{~s}$ at $170 \mathrm{GHz}$, and a total electrical efficiency of $50 \%$ for next step fusion devices. These developments are under fabrication. Up to now, the output power of $1 \mathrm{MW} / 1 \mathrm{~s}$ and 0.9 MW/9 s with $170 \mathrm{GHz}$ have been demonstrated [1].

In ITER, both $170 \mathrm{GHz}$ and $120 \mathrm{GHz} \mathrm{EC}$ waves will be installed; especially a $120 \mathrm{GHz}$ fundamental ordinary EC wave will be utilized for pre-ionization to assist current startup by $\mathrm{OH}$ coils [2]. On other tokamaks, source plasmas have been produced by the EC waves, and have contributed to the reduction of flux consumption in the plasma current start-up phase $[3,4]$. Source plasmas have also been utilized for current start-up using the combination of lower hybrid current drive (LHCD) to investigate the possibility of tokamak operation without the assistance of $\mathrm{OH}$ coils [5,6]. Source plasma ionized by the fundamental ordinary EC wave has been produced in the frequency range of 35-60 GHz. However, the plasma production has not been investigated in detail, and the frequency of the EC waves in previous experiments was far from $120 \mathrm{GHz}$ to $170 \mathrm{GHz}$. Furthermore, a simple model of the inductive breakdown phase with the assistance of EC wave has been proposed [3]. As, in this model, the ionization rate is derived from Townsend's avalanche theory, it is impossible to apply the RF induced breakdown. On the other hand, there have been many experiments regarding plasma production in Helical devices [7,8]. In these cases, plasmas are produced by EC waves without the assistance of flux injection. However, as helical systems have a closed flux surface without plasma current, the electron loss process is quite different. Hence, it is required that the characteristics of the source plasma produced by the high frequency EC wave be confirmed experimentally. In this paper, we describe the ECH system installed on TRIAM-1M, and the source plasma ionized by the $170 \mathrm{GHz} \mathrm{EC}$ wave. 


\section{2. $170 \mathrm{GHz}$ EC System on TRIAM-1M}

The TRIAM- $1 \mathrm{M}(R=0.8 \mathrm{~m}, a \times b=0.12 \times 0.18 \mathrm{~m})$ has 16 superconducting toroidal magnetic coils made of $\mathrm{Nb}_{3} \mathrm{Sn}$. These coils can generate toroidal magnetic fields, $B_{\mathrm{T}}$ up to 8 $\mathrm{T}$, at the centre of the plasma. On the TRIAM-1M, a gyrotron of $170 \mathrm{GHz}, 200 \mathrm{~kW}$, and $5 \mathrm{~s}$ has been installed for the breakdown, the plasma heating, and the current drive. Since the fundamental electron cyclotron resonance of $170 \mathrm{GHz}$ is 6.1 $\mathrm{T}$, the fundamental resonance layer can be set on the entire vacuum vessel by changing the toroidal magnetic fields from $5.5 \mathrm{~T}$ to $7.3 \mathrm{~T}$.

\subsection{Experimental apparatus of the 170 GHz EC system}

The RF power generated by the gyrotron is transmitted by a waveguide line which is composed of circular corrugated waveguides, miter bends, waveguide switches, and so on aslisted on Table 1. The arrangements of the components are shown in Fig. 1. The power loss of circular corrugated waveguides is about $0.013 \mathrm{~dB} / 100 \mathrm{~m}$ for the $\mathrm{HE}_{11}$ mode. Considering the power loss induced by other components, the total power loss due to transmission from the gyrotron to the TRIAM-1M is less than $0.2 \mathrm{~dB}$. The output power of the gyrotron is transmitted into Matching Optical Units (MOU), which convert microwaves to a Gaussian beam by means of the two mirrors inside of the MOU. The sizes of two mirrors are $170.3 \mathrm{~mm}$ width $160 \mathrm{~mm}$ height, and $90.5 \mathrm{~mm}$ width 85 $\mathrm{mm}$ height, respectively. The converted microwave is introduced into the circular corrugated wave-guides having diameters of $63.5 \mathrm{~mm}$, which transmit microwaves in the $\mathrm{HE}_{11}$ mode. The measured coupling of the wave beam at the MOU output and $\mathrm{HE}_{11}$ mode is sufficient in relation to the theoretical value of $98.6 \%$.

The microwave power is monitored at the miter bend by the placement of a power monitor. This miter bend has a slit for the leakage of microwave power by $-75 \mathrm{~dB}$. The leaked RF power through this slit is detected by a diode equipped with an attenuator. To measure the RF power, this power monitor has been calibrated with the help of a water-cooled dummy load, which can measure the absolute power by the increment of the water temperature. This power monitor can measure the RF power in both forward and backward directions. After passing the power monitor miter bend, the RF power goes through a waveguide switch to change the target, the TRIAM-1M or a dummy load. In the case of the gyrotron test, the RF power is transmitted to the dummy load. Three miter bends with an arc detector are installed in order to detect the arc in the waveguide line. When the arc detector works, the gyrotron is suspended swiftly within $5 \mu \mathrm{s}$. A DC break is installed for the electric insulation between the vacuum vessel and the gyrotron in order to protect the devices from each other, and to avoid forming a large electric loop. A vacuum pump out tees have a port to evacuate the waveguides at 17 liter/s. The waveguides are evacuated at less than $10^{-4}$ Pa.

Since the window may occasionally cause vacuum leakage due to the thermal heat load or the mechanical vibration of waveguides due to the opening and closing of the gate valve, the window is not set in this transmission line. Hence, when the experiments are conducted, the vacuum of the tokamak vessel is kept higher than $1.6 \times 10^{-4} \mathrm{~Pa}$. Therefore, the gas flows out from the vacuum vessel to the waveguides. The RF power goes through the taper waveguides to convert the diameter of wave-guides from $63.5 \mathrm{~mm}$ to $31.75 \mathrm{~mm}$ in order to introduce the RF power into the launcher. After going through the launcher, the RF power is injected into the vacuum vessel from the horizontal port of the vacuum vessel perpendicularly to the toroidal magnetic fields with the $\mathrm{HE}_{11}$ ordinary mode. The beam launched from the end of the launcher having a $31.75 \mathrm{~mm}$ diameter has a radius of $12 \mathrm{~mm}$ at the center of vacuum vessel. A part of the launched RF power can penetrate plasma without being absorbed, and reach the facing wall inside the vacuum vessel. A mirror at an angle of 20 degrees is installed on the facing wall in order to prevent the reflected power from going back to the launcher directly.

To generate and transmit the RF power properly, the gyrotron and RF components should be cooled. The cooling

Table 1 List of microwave components installed on the TRIAM-1M system

\begin{tabular}{|c|c|c|}
\hline & Components & Number \\
\hline (A) & Gyrotron & 1 \\
\hline (B) & Matching Optical Unit & 1 \\
\hline (C) & Power Monitor Miter Bends $63.5 \mathrm{~mm}$ & 1 \\
\hline (D) & Arc Detector Miter Bends $63.5 \mathrm{~mm}$ & 3 \\
\hline (E) & Waveguide Switch $63.5 \mathrm{~mm}$ & 2 \\
\hline (F) & Dummy Load (Gycom) & 1 \\
\hline (G) & Dummy Load (General Atomics) & 1 \\
\hline$(\mathrm{H})$ & Waveguide Bellows $63.5 \mathrm{~mm}$ & 2 \\
\hline (I) & Waveguide Bellows 31.75 mm & 1 \\
\hline$(\mathrm{J})$ & Vacuum Pumpout Tee 63.5 mm & 1 \\
\hline$(\mathrm{K})$ & Vacuum Pumpout Tee $31.75 \mathrm{~mm}$ & 1 \\
\hline$(\mathrm{L})$ & DC Break, 5 kV $63.5 \mathrm{~mm}$ & 1 \\
\hline (M) & Waveguide Taper $31.75 \mathrm{~mm}-63.5 \mathrm{~mm}$ & 1 \\
\hline$(\mathrm{N})$ & Gate Valve $31.75 \mathrm{~mm} 170 \mathrm{GHz}$ & 1 \\
\hline (O) & Launcher & 1 \\
\hline (P) & Corrugated Waveguide $63.5 \mathrm{~mm}$ & $5.05(\mathrm{~m})$ \\
\hline (Q) & Corrugated Waveguide $31.75 \mathrm{~mm}$ & $0.68(\mathrm{~m})$ \\
\hline
\end{tabular}

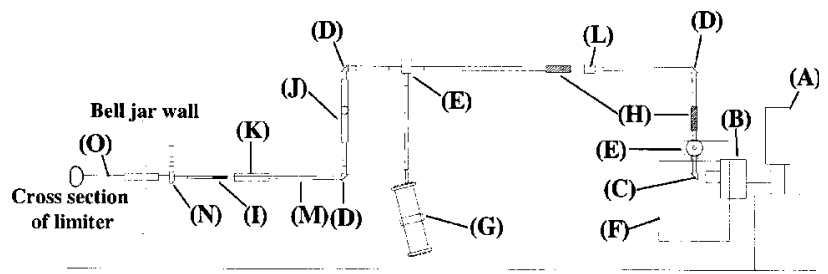

Fig. 1 RF transmission line power from the gyrotron to the vacuum vessel of the TRIAM-1M. The characters in this figure correspond to the components shown in Table. 1. 
system for this ECH system has the capability to achieve a flow rate of 1,600 litter/min and a heat exchange of $560 \mathrm{~kW}$. The flow rates of water to cool the gyrotron are 40 litter/min for the cavity, 1,000 litter/min for the collector, and 10 litter/ min for the window made of boron nitride. These flow rates and the pressures of flows are monitored all the time. When these values stray from the regulated ranges, the gyrotron is automatically suspended for protection.

\subsection{The results of the tests of the gyrotron}

In order to generate RF power properly, the fundamental parameters are set as follows: The heater voltage is set to 93.0 $\mathrm{V}$ with $400 \mathrm{~Hz}$. The current of the superconducting cryomagnet of the gyrotron is optimized at $68.5 \mathrm{~A}$, which produces maximum magnetic fields of $6.7 \mathrm{~T}$ in the cavity of the gyrotron. The gun coil current and collector coil current are $1.5 \mathrm{~A}$ and $35.0 \mathrm{~A}$, respectively. The gyrotron installed on the TRIAM-1M is not the collector potential depression (CPD) type, while its electron gun is the diode type. Output tests were conducted under these optimized parameters. When these tests were performed, the dummy load was utilized as the target of RF power.

Short RF pulses of $100 \mathrm{~ms}$ are made to find the optimized beam voltage, $V_{\text {beam }}$. The beam voltages are raised to within $10 \mathrm{~ms}$, kept constant for $100 \mathrm{~ms}$, and lowered within $10 \mathrm{~ms}$. The constant beam voltage, $V_{\text {beam }}$, is changed from 56 to $65 \mathrm{kV}$ shot by shot. A beam voltage higher than $65 \mathrm{kV}$ cannot be supplied for the protection of the gyrotron. A beam voltage lower than $56 \mathrm{kV}$ is not supplied to suppress the excitation of parasitic modes. The calculated dependencies of the beam voltage, $V_{\text {beam }}$, on the efficiencies of the operating mode and the parasitic mode are shown in Fig. 2. The efficiency of the parasitic mode increases abruptly with the decrease of the beam voltage under $56 \mathrm{kV}$, and the parasitic mode become the dominant mode compared to the operating mode. Hence, the supplied beam voltage is restricted within 56 to $65 \mathrm{kV}$.

The test results for the optimum beam voltage are shown in Fig. 3. The output power, $P_{\mathrm{RF}}$, is increased with the beam voltage, and it seems to be saturated around $P_{\mathrm{RF}}=200 \mathrm{~kW}$ (Fig. 3(a)). The consumption of electricity is also increased with $V_{\text {beam }}$ (Fig. 3(b)). The ratio of the output RF power to the consumption of electricity is shown in Fig. 3(c). The ratio is increased with $V_{\text {beam }}$, and saturated around $65 \mathrm{kV}$. Thus, the optimum beam voltage is $65 \mathrm{kV}$.

It is important to confirm the frequency of the RF wave generated by the gyrotron, which defines the magnetic field of the electron cyclotron resonance, and it is also important to confirm that this frequency is stable during the discharge. In the case of a long discharge, the frequency of the RF wave may change due to the temperature rise of the cavity of the gyrotron, the unstable power supply, and so on. Thus, the frequency of the RF wave generated by the gyrotron was measured during the $5 \mathrm{~s}$ discharge using a frequency meter. The result is shown in Fig. 4. The frequency decreases from 169.92 $\mathrm{GHz}$ to $169.89 \mathrm{GHz}$ during the $5 \mathrm{~s}$ discharge. This

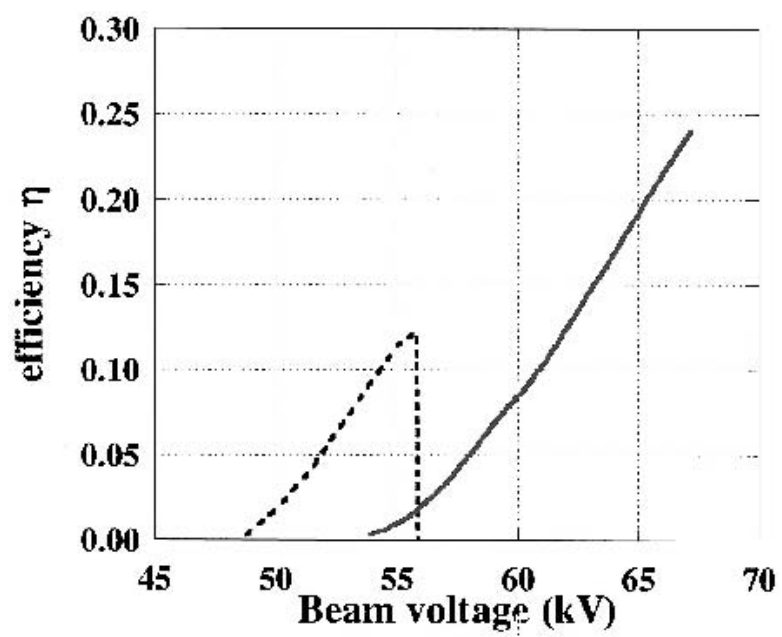

Fig. 2 The calculated dependence of the beam voltage on the efficiency of the operating mode (solid line) and the parasitic mode (dashed line).
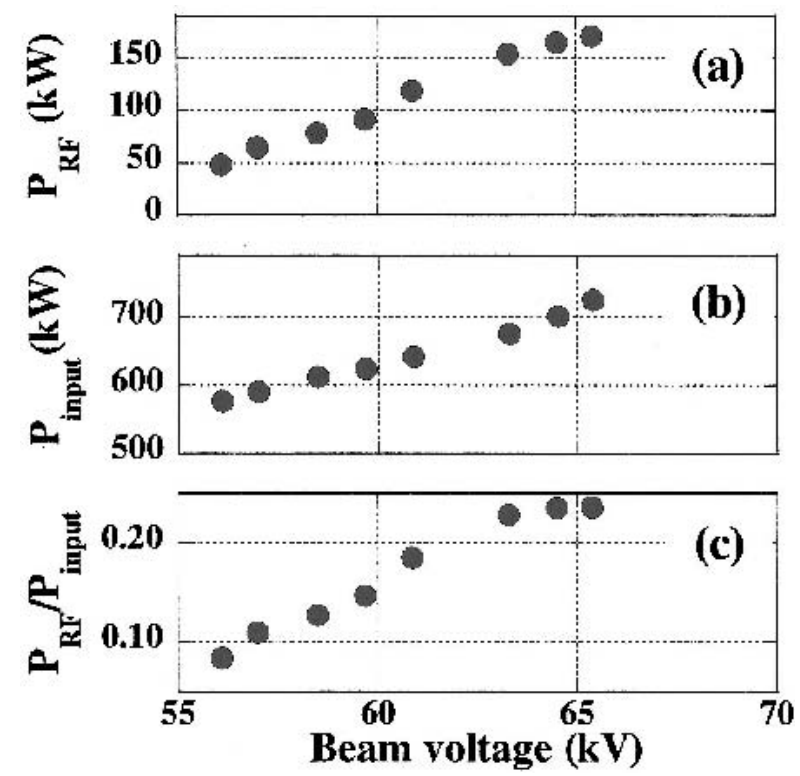

Fig. 3 Beam voltage vs. (a) output RF power, $P_{R F}$, (b) consumption of electricity, $\mathrm{P}_{\text {input, }}(\mathrm{c})$ the ratio of $\mathrm{RF}$ power to consumption of electricity, $\mathrm{P}_{\mathrm{RF}} / \mathrm{P}_{\text {input }}$.

means that the position of the resonance layer moves outward less than $0.5 \mathrm{~mm}$ due to this decrease of frequency during the $5 \mathrm{~s}$ discharge. Hence, this decrease of frequency is negligible, and the position of the resonance layer remains constant during a $5 \mathrm{~s}$ discharge.

In order to test the continuous regulation of RF power, the beam voltage, $V_{\text {beam }}$, was increased from $56 \mathrm{kV}$ to $64 \mathrm{kV}$ within $5 \mathrm{sec}$ (Fig. 5(a)). Although the beam current, $I_{\text {beam }}$ is nearly constant $16 \mathrm{~A}$ (Fig. 5(b)), the output power of gyrotron was increased from $85 \mathrm{~kW}$ up to $200 \mathrm{~kW}$ (Fig. 5(c)) with the beam voltage, $V_{\text {beam }}$. From this test, it is found that the RF power could be controlled by the change of the beam voltage in the range of $P_{\mathrm{RF}}=85 \mathrm{~kW}-200 \mathrm{~kW}$. 


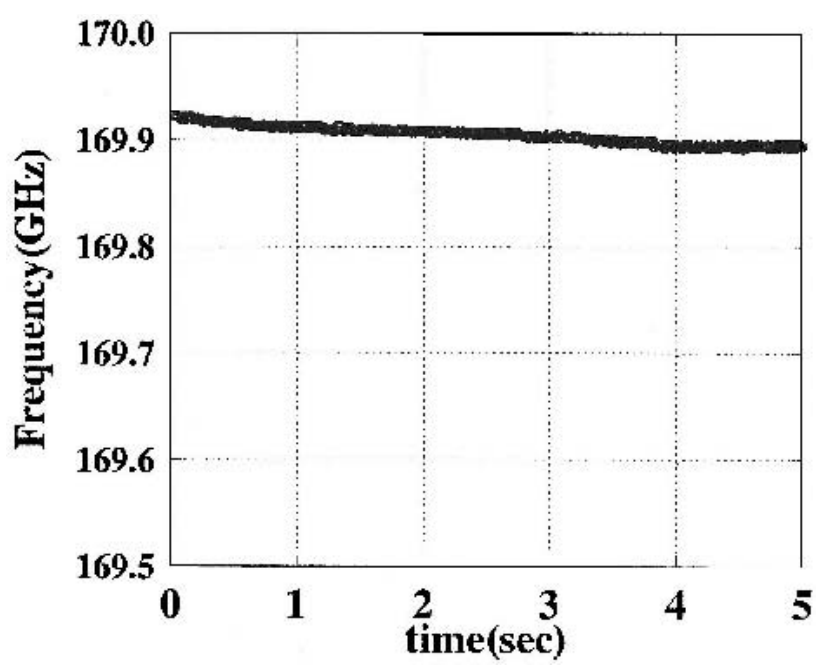

Fig. 4 The operating frequency of the $170 \mathrm{GHz}$ gyrotron for a 5 sec discharge.

\section{Experimental Results of Plasma Production}

After the gyrotron test using the dummy load, the RF power injection into TRIAM-1M was conducted in order to make the source plasma. Since the cut-off density for the 170 $\mathrm{GHz}$ fundamental $\mathrm{O}$-mode is $3.6 \times 10^{20} \mathrm{~m}^{-3}$, the EC wave goes from the launcher to the confrontational wall, and is expected to resonate at the position of an electron cyclotron resonance. Since an electron cyclotron frequency is much larger than plasma frequency $\left(\omega_{\mathrm{ce}} » \omega_{\mathrm{pe}}\right)$ because of the high magnetic field, the position of upper-hybrid resonance $\left(\omega_{\mathrm{UH}}\right.$ $\left.=\sqrt{\omega_{\mathrm{ce}}^{2}+\omega_{\mathrm{pe}}^{2}}\right)$ is simply considered the same as to the electron cyclotron resonance.

The magnetic field of the cyclotron resonance is $6.1 \mathrm{~T}$ at a frequency of $170 \mathrm{GHz}$. Since the toroidal magnetic field strength is defined as the value of the position of $R=0.80 \mathrm{~m}$ on the TRIAM-1M, the toroidal magnetic field is set in order to $6.4 \mathrm{~T}$ to locate the resonance layer at the center of the vacuum vessel $(R=0.84 \mathrm{~m})$. To confirm the position of the resonance experimentally, the toroidal magnetic field is adjusted within $6.0-6.7 \mathrm{~T}$. Figure 6 shows the radial profile of the soft x-ray signal in the cases of $B_{\mathrm{T}}=6.0,6.4$, and 6.7 $\mathrm{T}$. The calculated positions of the electron cyclotron resonance are $0.79,0.84$, and $0.88 \mathrm{~m}$, respectively. The peaks of the radial profile of the soft $\mathrm{x}$-ray signal are close to the calculated resonance positions.

Since the calculated one-pass absorption rate of the fundamental ordinary mode is less than $3 \%$ with the parameters of the plasma density, $n_{\mathrm{e}}=1 \times 10^{19} \mathrm{~m}^{-3}$, electron temperature, $T_{\mathrm{e}}=100 \mathrm{eV}$, and the frequency of EC wave, 170 $\mathrm{GHz}$, most of the EC power injected into the TRIAM-1M goes from the launcher to the facing wall, and is reflected at the mirror at an angle of 20 degrees. This multi-reflection may contribute to the total absorption.

The toroidal magnetic field is set to $6.0 \mathrm{~T}$ in order to locate the resonance layer on $R=0.80 \mathrm{~m}$. An EC wave of

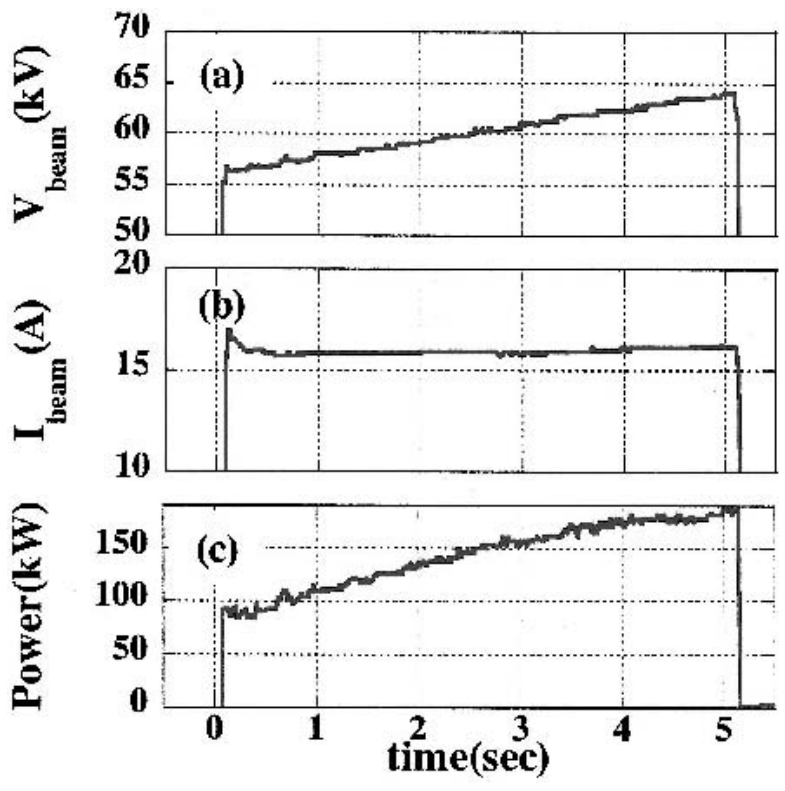

Fig. 5 Waveform of (a) beam voltage, $V_{\text {beam }}$ (b) beam current, $\mathrm{I}_{\text {beam, }}$ and (c) power in the case of increasing the beam voltage from $56 \mathrm{kV}$ to $64 \mathrm{kV}$.

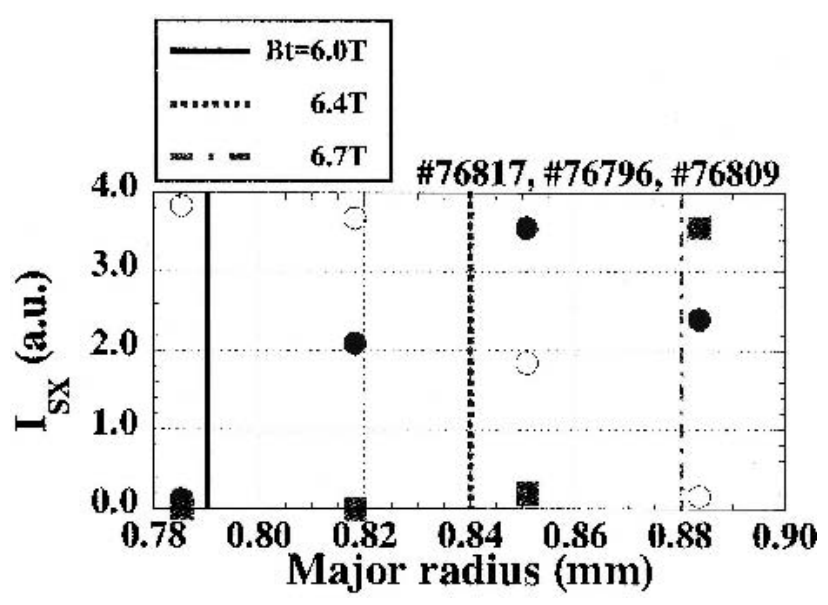

Fig. 6 The radial profiles of the soft $x$-ray signal of the toroidal magnetic fields $\mathrm{B}_{\mathrm{T}}=6.0 \mathrm{~T}$ (open circle), $\mathrm{B}_{\mathrm{T}}=6.4 \mathrm{~T}$ (closed circle), and $B_{T}=6.7 T$ (closed square) and the calculated positions of the resonance layer (lines).

$120 \mathrm{~kW}$ was injected for $300 \mathrm{~ms}$. Fig. 7 (a) shows the time evolution of the injected and the reflected power detected by the power monitor during plasma production by the EC wave. Fig. 7 (b) shows the time evolution of plasma density. Election density measured using a $140 \mathrm{GHz}$ interferometer is kept almost constant at $0.7 \times 10^{19} \mathrm{~m}^{-3}$. Since the reflected power is negligible, the reflected power does not seem to go back to the launcher directly. Thus, the EC wave is safely injected into the TRIAM-1M and the source plasma of a density of $0.7 \times 10^{19} \mathrm{~m}^{-3}$ can be produced. The position of the source plasma is indistinctly localized around the resonance layer with a half full-width of $0.1 \mathrm{~m}$ (Fig. 6), which is shorter than the size of vessel, $2 a \approx 0.24 \mathrm{~m}$.

An investigation of the effect of varying the power of 


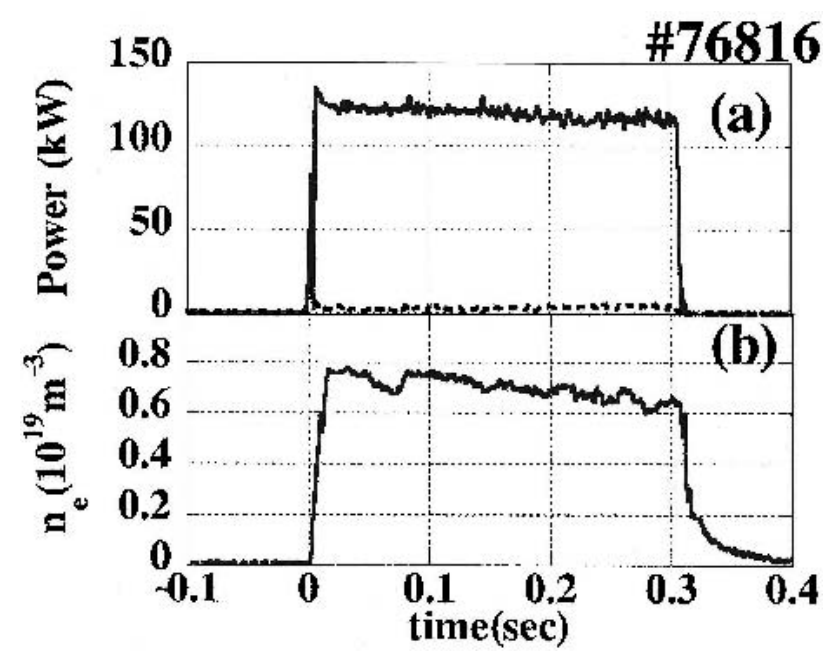

Fig. 7 Time evolutions of (a) the injected power (solid line) and the reflected power (dashed line) of the EC wave monitored by the power monitor, and (b) plasma density, $\mathrm{n}_{\mathrm{e}}$ measured using the $140 \mathrm{GHz}$ interferometer. The toroidal magnetic field is 6.0T.

the EC wave, $P_{\mathrm{RF}}$ was carried out in the range of $P_{\mathrm{RF}}=40-$ $100 \mathrm{~kW}$, and $300 \mathrm{~ms}$. The toroidal magnetic field was set to $6.4 \mathrm{~T}$ in order to locate the resonance layer on the centre of the vacuum vessel $(R=0.84 \mathrm{~m})$, and the pressure of the tokamak vessel was $1.3 \times 10^{-3} \mathrm{~Pa}$. The plasma density was measured using a $140 \mathrm{GHz}$ interferometer. Fig. 8 (a) shows the typical time evolution of the power of the $\mathrm{EC}$ wave and the plasma density. The plasma density was $1 \times 10^{19} \mathrm{~m}^{-3}$ at a power of $92 \mathrm{~kW}$. It takes $100 \mathrm{~ms}$ from the beginning of the EC wave injection for the breakdown to occur. Fig. 8 (b) shows the dependence of $P_{\mathrm{RF}}$ on the electron density. The plasma density increases with $P_{\mathrm{RF}}$, and is saturated in the range of $P_{\mathrm{RF}}=70-100 \mathrm{~kW}$. Fig. 8 (c) shows the dependence of $P_{\mathrm{RF}}$ on the delay time of the initiation of the breakdown. The delay time decreases with the increase of $P_{\mathrm{RF}}$, and is 50 - $100 \mathrm{~ms}$ at $P_{\mathrm{RF}}=90 \mathrm{~kW}$. However, the breakdown does not occur at $P_{\mathrm{RF}}=40 \mathrm{~kW}$ within a pulse length of $300 \mathrm{msec}$.

\section{Discussion}

The plasma breakdown occurs under different conditions in tokamaks and stellarators. In stellarators, the confining magnetic field structure is generated by external coils, and magnetic confinement is provided from the beginning of the plasma breakdown, whereas in tokamaks the confinement is imperfect in the breakdown phase and sensitive to error fields, which necessitate an increase in the electric fields required for the breakdown. The required electric fields for the breakdown are also increased with the frequency of the EC wave since the electrons can't get sufficient energy to ionize the neutral gas in the case of higher frequencies. In the WT-2 the required power for the breakdown was lower than $30 \mathrm{~kW}$ at a frequency of $35.6 \mathrm{GHz}$ [9], whereas in the TRIAM the required power was higher than $40 \mathrm{~kW}$.

The power required for the breakdown has been
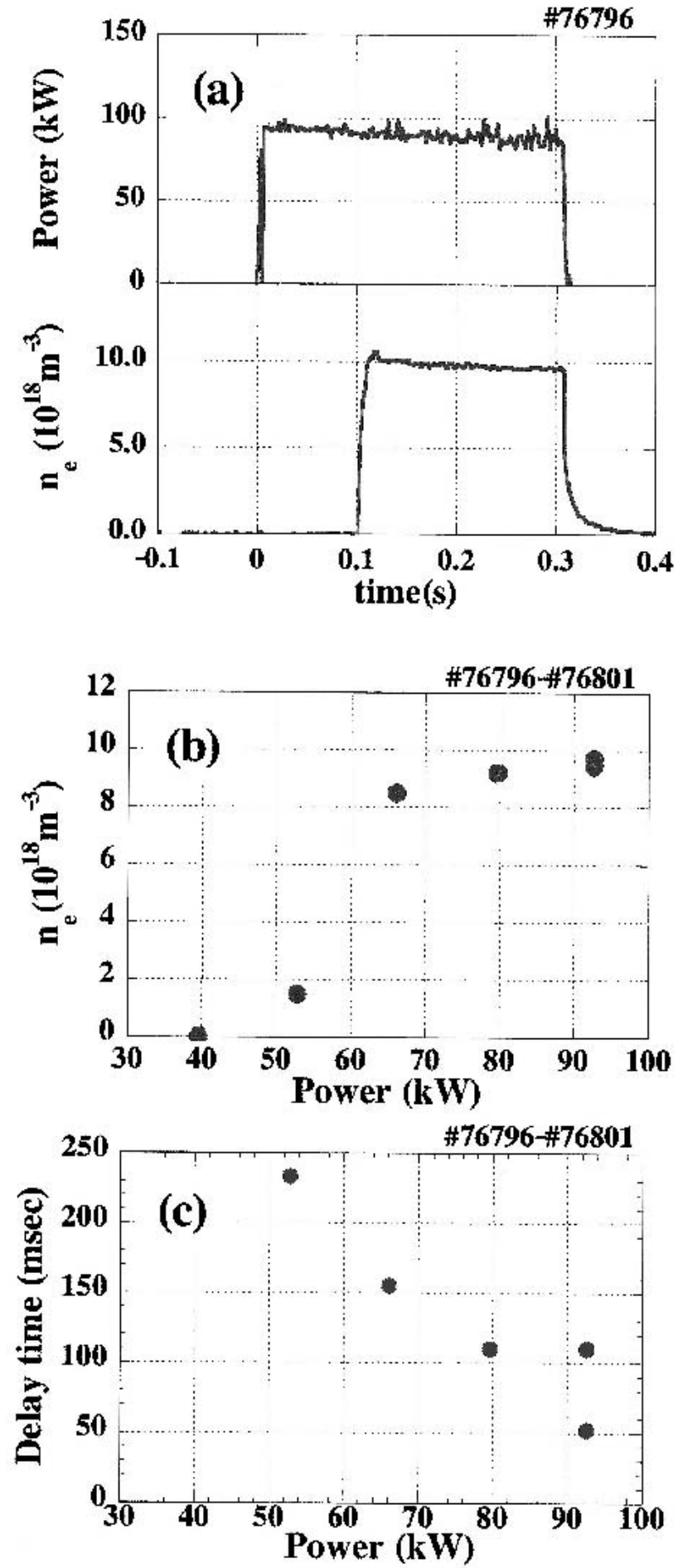

Fig. 8 The effect of varying the power of the EC wave, $P_{R F}$. (a) time evolution of the power of the EC wave, $\mathrm{P}_{\mathrm{RF}}$, and plasma density, $n_{e}$, (b) the dependence of $P_{R F}$ on $n_{e}$. (c) the dependence of $\mathrm{P}_{\mathrm{RF}}$ on the delay time of the initiation of the breakdown. The toroidal magnetic field is $6.4 \mathrm{~T}$.

predicted theoretically in the case of non-static electric fields [10]. Fig. 9 shows the evaluated power necessary for the breakdown using this theoretical model. Though one should keep in mind that this model doesn't include the effects of the electron cyclotron resonance, and that the evaluated power for the breakdown is overestimated, the evaluated power for 


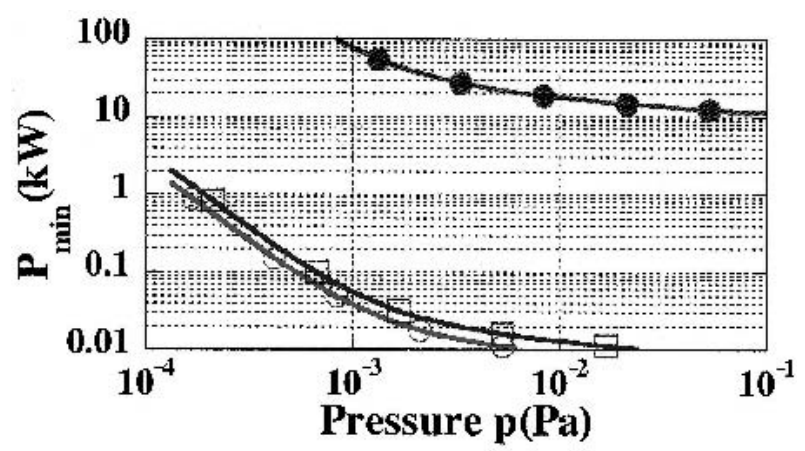

Fig. 9 The required power for the breakdown evaluated by the theoretical model, not including the effects of the electron cyclotron. The frequencies of the EC wave are $2.45 \mathrm{GHz}$ (open circle), $8.2 \mathrm{GHz}$ (open square), and 170 $\mathrm{GHz}$ (closed circle).

the breakdown of the $170 \mathrm{GHz} \mathrm{EC}$ wave is over 1,000 times larger than that of the $2.45 \mathrm{GHz}$ and $8.2 \mathrm{GHz} \mathrm{EC}$ waves.

\section{Summary}

An ECH system has been installed on the TRIAM-1M, and has worked smoothly with the capabilities of $5 \mathrm{~s}$ discharge, $200 \mathrm{~kW}$ output power, and $170 \mathrm{GHz}$ frequency. The optimized beam voltage is found to be $V_{\text {beam }}=65 \mathrm{kV}$, and the output power detected by a power monitor and the electricity consumption are $200 \mathrm{~kW}$ and $725 \mathrm{~kW}$, respectively. To make source plasma, the $170 \mathrm{GHz}$ fundamental ordinary EC wave was injected into the vacuum vessel of TRIAM-1M in order to ionize the neutral gas. While the breakdown didn't occur at $P_{\mathrm{RF}}=40 \mathrm{~kW}$ with the neutral gas pressure, $p=1.3 \times$
$10^{-3} \mathrm{~Pa}$, the density of this source plasma increased up to 1.0 $\times 10^{19} \mathrm{~m}^{-3}$ at $P_{\mathrm{RF}}=100 \mathrm{~kW}$.

\section{Acknowledgements}

The authors would like to thank the GYCOM company for its large amount of technical support and for providing the helpful datasets.

One of the authors (M.S.) is grateful to Dr. F. Leuterer and his colleagues for their useful discussions and comments.

\section{References}

[1] T. Imai, N. Kobayashi et al., Fusion Eng. Des. 55, 281 (2001).

[2] ITER Physics Expert Group on Diagnostics, ITER Physics Basis Editors, Nucl. Fusion 39, 2577 (1999).

[3] B. Lloyd, G.L. Jackson et al., Nucl. Fusion 31, 2031 (1991).

[4] K. Hoshino and T. Yamamoto, J. Phys. Soc. Jpn. 54, 2503 (1985).

[5] K. Ogura, H. Tanaka, S. Ide et al., Nucl. Fusion 30, 611 (1990).

[6] K. Toi, K. Ohkubo, K. Kawahata et al., Nucl. Fusion 28, 147 (1988).

[7] J.N. Talmadge and D.T. Anderson, Nucl. Fusion 28, 1879 (1988).

[8] A. Cappa, F. Castejon, F.L. Tabares et al., Nucl. Fusion 41, 363 (2001).

[9] S. Kubo and M. Nakamura, Phys. Rev. Lett. 50, 1994 (1983).

[10] A.D. Macdonald, C. Sanborn and C. Brown, Phys. Rev. 75, 411 (1949). 